\title{
Natal and Neonatal Teeth: A Retrospective Study of 15 Cases
}

\author{
Nagaveni N Basavanthappa ${ }^{a}$ \\ Umashankara Kagathur ${ }^{b}$ \\ Radhika N Basavanthappac \\ Satisha T Suryaprakash ${ }^{d}$
}

\section{ABSTRACT}

Objectives: To present 17 natal/neonatal teeth in 15 patients and describe their clinical characteristics, associated disorders, complications and treatment.

Methods: A retrospective study of neonates who visited the Department of Pedodontics and Preventive Dentistry, College of Dental Sciences, Davangere, India, between 2003 and 2006 was carried out. It was a study of clinical data, such as the age and gender of the patients, the history and chief complaints of mothers, the clinical appearance and location of natal/neonatal teeth, and associated complications and treatments.

Results: A total of 17 teeth (6 natal, 11 neonatal) were found in 15 patients. No significant gender predilection ( 8 male, 7 female) was found. Sixteen natal/neonatal teeth were placed in mandibular incisor area ( 10 on the right side and 6 on the left side) and one tooth in the maxillary incisor area. In 13 patients, the occurrence of natal/neonatal teeth was unilateral, and in 2 patients, it was bilateral. Three cases were associated with enamel hypoplasia, 3 cases with Riga-Fede disease, and 1 case with gingival hyperplasia. One case involved a patient with cleft lip and palate. Radiographic examination confirmed these teeth to be supernumerary, and all teeth exhibited hypermobility. Extraction had been done in all the cases. Eleven of the extracted teeth exhibited only rudimentary roots, and six teeth showed no roots.

Conclusions: The occurrence of a natal/neonatal tooth is a rare phenomenon. When it occurs, the teeth have a variety of clinical characteristics and lead to different complications. Knowledge of the management of these structures is essential for the overall well being of a child. (Eur J Dent 2011;5:168-172)

Key words: Natal tooth; Neonatal tooth; Vitamin K; Riga-Fede disease; Gingival hyperplasia; Cleft lip and palate.

\footnotetext{
a Assistant Professor, Department of Pedodontics \& Preventive Dentistry, College of Dental Sciences, Davangere, India.

b Associate Professor, Department of Oral \& Maxillofacial Surgery, College of Dental Sciences, Davangere, India.

c Senior Lecturer, Department of Orthodontics, School of Dentistry, Krishna Institute of Health Sciences, Karad, Maharashtra, India.
}

d Resident (Periodontics), Department of Dental Surgery, Armed Forces Medical College, Pune, Maharashtra, India.

- Corresponding author: Dr. Nagaveni N Basavanthappa Department of Pedodontics \& Preventive Dentistry, College of Dental Sciences, Davangere, Karnataka, India. Phone: +919675129388

E-mail: nagavenianuragdagmail.com 


\section{INTRODUCTION}

Eruption of the first tooth in a baby's first year of life is one of his or her major milestones. Infants occasionally are born with structures that appear to be erupted teeth well before the first deciduous teeth are expected. These precociously and prematurely erupted teeth lead to a plethora of reactions, which are combined with many misconceptions and have an impact on functional and psychological changes in the child's life and emotions of the parents. These structures must be differentiated from true deciduous teeth, so they are called natal and neonatal teeth. Massler and Savara' defined "natal teeth" as teeth present at birth and "neonatal teeth" as those that erupt within the first month of life.

The etiology of these teeth is still unknown. A number of factors favoring the occurrence of these teeth have been described in the literature 2-11 $^{-1 T a b l e ~ 1) . ~ S o m e ~ i n v e s t i g a t o r s ~ s u g g e s t e d ~}$ that natal/neonatal teeth are associated with various syndromes or systemic conditions ${ }^{12-15}$ (Table 1). Therefore careful evaluation of infants with natal or neonatal teeth is recommended.

Natal and neonatal teeth provoke the interest of both parents and the dentist because of their varied clinical features. The aim of this paper is to present information regarding 17 natal/neonatal teeth in 15 patients and to describe the clinical characteristics, associated disorders, and treatments.

\section{MATERIALS AND METHODS}

This was a retrospective study of Indian neonates who reported to the Department of Pedodontics and Preventive Dentistry, College of Dental Sciences, Davangere, India, between 2003 and 2006 using the laboratory data. A total of 17 natal or neonatal teeth were found in 15 neonates. The authors reviewed clinical data, such as the age and gender, the history and chief complaints of mothers, clinical appearance and location of natal/neonatal teeth, and associated complications and treatments. Intraoral photographs and radiographs had been taken in all patients. The variables were analyzed for sexual dimorphism, different locations, and single or multiple occurrences, different clinical features, and complications.

\section{RESULTS}

Among 15 patients, 17 teeth 16 natal, 11 neonatall were diagnosed in 15 patients who were 8 days to one month old (Table 2). There was no significant gender preference ( 8 male, 7 female). A significant single occurrence of natal/neonatal teeth was observed as shown in Table 2. Of the 15 patients, only two patients were diagnosed with more than one tooth either simultaneously (case 7) or at short intervals of time (case 11). There was a significant preference for the mandibular incisor position. No significant difference was found as far as the side of the mouth where the tooth erupted, although the number of natal/neonatal tooth was higher on the right side (ten teeth) than on the left side (six teeth). In the mandible, a majority (16/17) of natal/neonatal teeth involved the central incisor position; in one patient, a tooth in the maxillary incisor area was visible. Clinical histories were checked for symptoms, and in all cases, there was a difficulty in feeding or refusal to suckle milk due to pain. The reasons for making a first visit to a dentist were the appearance of the tooth and its mobility, presence of sublingual ulceration, refusal to suckle, and possible aspiration of the tooth because of mobility. A natal tooth associated with cleft lip and palate was observed in one patient. Clinically, three patients (cases 1, 11, and 13) exhibited enamel hypoplasia of the natal/ neonatal tooth, one patient showed gingival hyperplasia (case 7), and three patients displayed sublingual ulceration (cases 5, 9 and 14). The natal/ neonatal teeth in all patients exhibited hyper mobility. A radiographic examination of all patients confirmed that these teeth were supernumerary. Extraction was performed in all 15 cases under topical anesthesia, since all were hyper mobile and mothers of all patients were willing to have these teeth removed. Eleven of extracted teeth exhibited rudimentary roots, and six teeth showed no roots.

Table 1. Hypothetical factors underlying natal/neonatal teeth.

- Familial pattern like hereditary transmission of a dominant

autosomal gene..$^{2-4}$

- Endocrinal disturbances. 5

- Superficial position of tooth germs. ${ }^{6}$

- Osteoblastic activity within area of the tooth germs. ${ }^{7}$

- Febrile status; eruption accelerated by febrile incidents.

- Infection or malnutrition.?

- Nutritional deficiency, e.g., Hypovitaminosis. ${ }^{10}$

- Environmental factors. ${ }^{11}$

- Association with syndromes and systemic conditions. ${ }^{12-15}$ 


\section{DISCUSSION}

In the general population, the prevalence of natal or neonatal teeth ranges from 1:1,000 to $1: 30,000$, depending on the type of study and occurring in general with incidences of one or two teeth. ${ }^{16,17}$ The highest prevalence was found in the only study that relied on personal examination of patients. ${ }^{7}$ Other researchers found it to be found in approximately 1 in 2,000 - 3,500 births. ${ }^{1,2}$ DiazRomero et $\mathrm{al}^{18}$ stated that neonatal teeth were presented at a higher rate in the Mexican population. A rate of 1:716 is the highest ratio reported by Kates et al. ${ }^{7}$
The incidence of natal/neonatal teeth revealed no significant differences according to gender. Previous studies reported a higher frequency of occurrence in females. ${ }^{7.16-18}$ It has been reported that natal teeth are more frequent, approximately three times more common than neonatal teeth. ${ }^{19}$ Among them, $85 \%$ of natal or neonatal teeth are mandibular incisors followed by maxillary incisors $(11 \%)$, mandibular canines or molars $(3 \%)$, and maxillary canines or molars $(1 \%) .{ }^{19}$ Natal or neonatal canines are extremely rare. ${ }^{16}$ One researcher noted that natal/neonatal teeth occur more frequently bilaterally (61-76\%). ${ }^{19}$ On the contrary,

Table 2. Clinical characteristics of natal/neonatal teeth.

\begin{tabular}{|c|c|c|c|c|c|c|c|}
\hline Case No. & Age (Days) & Sex & $\begin{array}{c}\text { Natal/ } \\
\text { neonatal } \\
\text { teeth position }\end{array}$ & History and chief complaints & Clinical features & $\begin{array}{l}\text { Associated disorders \& } \\
\text { complications }\end{array}$ & Treatment \\
\hline 1. & 15 & Male & 81 & $\begin{array}{c}\text { Tooth erupted } 7 \text { days after birth } \\
\text { Difficulty in suckling }\end{array}$ & $\begin{array}{l}\text { Mobile, } \\
\text { Yellowish color }\end{array}$ & Enamel hypoplasia & Extraction \\
\hline 2. & 19 & Female & 81 & $\begin{array}{l}\text { Tooth present at the time of birth. } \\
\text { Difficulty in suckling }\end{array}$ & $\begin{array}{c}\text { Mobile, } \\
\text { Whitish color }\end{array}$ & None & Extraction \\
\hline 3. & 16 & Male & 51 & $\begin{array}{l}\text { Tooth present at the time of birth } \\
\text { Fear of aspiration due to mobility }\end{array}$ & $\begin{array}{c}\text { Mobile, } \\
\text { Whitish color }\end{array}$ & Cleft lip and palate & Extraction \\
\hline 4. & 14 & Female & 81 & $\begin{array}{c}\text { Tooth erupted } 15 \text { days after birth } \\
\text { Refusal to suckling }\end{array}$ & $\begin{array}{c}\text { Mobile, } \\
\text { Whitish color }\end{array}$ & None & Extraction \\
\hline 5. & 8 & Male & 81 & $\begin{array}{l}\text { Tooth present at the time of birth } \\
\text { Difficulty in feeding } \\
\text { Continuously cry }\end{array}$ & $\begin{array}{c}\text { Mobile, } \\
\text { White color }\end{array}$ & $\begin{array}{c}\text { Riga-Fede disease } \\
\text { (sublingual ulceration] }\end{array}$ & $\begin{array}{l}\text { Vitamin } \mathrm{K} \\
\text { administration + } \\
\text { Extraction }\end{array}$ \\
\hline 6. & 18 & Female & 71 & $\begin{array}{l}\text { Tooth erupted } 10 \text { days after birth } \\
\text { Refusal to suck milk } \\
\text { Continuously cry }\end{array}$ & $\begin{array}{c}\text { Mobile, } \\
\text { White color }\end{array}$ & None & Extraction \\
\hline 7. & 30 & Female & 71,81 & $\begin{array}{l}\text { Two teeth erupted } 15 \text { days after birth } \\
\text { Refusal to suck milk } \\
\text { Continuously cry }\end{array}$ & $\begin{array}{c}\text { Mobile, } \\
\text { Inflammation of } \\
\text { gingiva around the } \\
\text { teeth }\end{array}$ & Gingival hyperplasia & Extraction \\
\hline 8. & 25 & Male & 81 & $\begin{array}{l}\text { Teeth erupted } 15 \text { days after birth } \\
\text { Difficulty in feeding } \\
\text { Continuously cry }\end{array}$ & $\begin{array}{l}\text { Mobile, Whitish } \\
\text { color }\end{array}$ & None & Extraction \\
\hline 9. & 18 & Male & 71 & $\begin{array}{c}\text { Tooth erupted } 11 \text { days after birth } \\
\text { Refusal to suckling }\end{array}$ & $\begin{array}{l}\text { Mobile, } \\
\text { Whitish- opaque } \\
\text { in color }\end{array}$ & Riga-Fede disease & Extraction \\
\hline 10. & 17 & Female & 81 & $\begin{array}{c}\text { Tooth present at the time of birth. } \\
\text { Refusal to suckling }\end{array}$ & $\begin{array}{c}\text { Mobile, } \\
\text { Whitish color }\end{array}$ & None & Extraction \\
\hline 11. & 23 & Male & 71,81 & $\begin{array}{l}\text { Tooth erupted } 10 \text { days after birth fol- } \\
\text { lowed by another tooth after } 15 \text { days } \\
\text { Difficulty in feeding }\end{array}$ & $\begin{array}{l}\text { Mobile, } \\
\text { Yellowish color }\end{array}$ & Enamel hypoplasia & Extraction \\
\hline 12. & 21 & Female & 71 & $\begin{array}{c}\text { Teeth erupted } 15 \text { days after birth } \\
\text { Refusal to suck milk }\end{array}$ & $\begin{array}{l}\text { Mobile, } \\
\text { Whitish- opaque } \\
\text { color }\end{array}$ & None & Extraction \\
\hline 13. & 7 & Male & 81 & $\begin{array}{l}\text { Tooth present at the time of birth } \\
\text { Difficulty in feeding }\end{array}$ & $\begin{array}{l}\text { Mobile, } \\
\text { Yellowish- brown } \\
\text { color }\end{array}$ & Enamel hypoplasia & $\begin{array}{l}\text { Vitamin } \mathrm{K} \\
\text { administration + } \\
\text { Extraction }\end{array}$ \\
\hline 14. & 20 & Male & 81 & $\begin{array}{c}\text { Tooth erupted } 10 \text { days after birth } \\
\text { Difficulty in feeding }\end{array}$ & $\begin{array}{l}\text { Mobile, } \\
\text { Whitish- opaque } \\
\text { color }\end{array}$ & Riga-Fede disease & Extraction \\
\hline 15. & 21 & Female & 71 & $\begin{array}{l}\text { Tooth erupted at the time of birth } \\
\text { Refusal to suckling }\end{array}$ & $\begin{array}{l}\text { Mobile, } \\
\text { White color }\end{array}$ & None & Extraction \\
\hline
\end{tabular}


our study found more unilateral occurrences of natal/neonatal teeth. Ooshima et $a^{6}$ emphasized that multiple natal/neonatal teeth are extremely rare. The strong predilection for the lower central incisors is not surprising in view of the fact that they are normally the first teeth to erupt. Authors have stated that most commonly, natal/neonatal teeth are precociously erupted from the normal complement of primary teeth (90\%-99\%) and only $1 \%$ to $10 \%$ of natal and neonatal teeth are supernumerary. ${ }^{20,21}$ However, in the present study radiographic examination confirmed that all teeth were supernumerary teeth, which differed from information presented in other reports. ${ }^{1-3,7}$ In our study, 16 teeth occurred in the mandibular incisor area, one in the maxillary incisor area. No teeth were found in the molar/canine area. This is in line with information reported by other researchers. ${ }^{22,23}$ The present study showed a greater number of neonatal teeth than natal. This finding was not in agreement with findings of other studies. ${ }^{7,23}$

Clinically the natal/neonatal teeth are poorly developed and are small and cone shaped. They have a yellowish-brown or whitish opaque color and have a hypoplastic enamel or dentin. ${ }^{22}$ Occasionally they may be of normal size and shape. In our study, all teeth showed a small crown, and some teeth had rudimentary roots. Seven teeth were found to have no roots. In three cases, the teeth were a yellowish-brown color, suggesting an enamel hypoplasia.

Natal or neonatal teeth are more frequently seen in children with cleft lip and palate. Our study showed one case associated with a cleft lip and palate. A natal tooth with mobility was observed in the cleft region between the premaxilla and the maxilla. When a patient with a cleft lip and palate has natal/neonatal teeth, they interfere with the fabrication and application of the naso-alveolar molding appliance. ${ }^{24}$ Therefore, the tooth must be removed to facilitate the fabrication and placement of the device. Ziai et $\mathrm{al}^{24}$ suggested that although general anesthesia is not always indicated for the removal of these teeth, in cases in which the premaxilla is loose, general anesthesia is warranted. In our case, this problem was not encountered, and extraction had been done under topical anesthesia.

A major complication from natal/neonatal teeth is ulceration on the ventral surface of the tongue caused by the tooth's sharp incisal edge. This condition is also known as Riga-Fede disease or syndrome. ${ }^{25,26}$ Constant trauma may create ulceration sufficient to interfere with proper suckling and feeding and put the neonate at risk for nutritional deficiencies and cause infants' failure to gain weight. ${ }^{25}$ Treatment of Riga-Fede disease has varied over the years. Early treatment consisted of excision of the lesion. In case of mild to moderate irritation to the tongue, experts advocate conservative treatment, such as smoothing the incisal edge with an abrasive instrument. ${ }^{20}$ Alternatively, a small increment of composite resin may be bonded to the incisal edges of the teeth. ${ }^{27}$ In case these is a large ulcerated area, even after reducing incisal edges, the teeth may still contact and traumatize the tongue during suckling, enough to delay healing. ${ }^{28}$ So for rapid resolution of the lesion, extraction of these teeth is mandatory instead of using more conservative methods.

The reason usually given for eruption of teeth during the perinatal period is a superior position of the tooth germ. ${ }^{6}$ However, in most cases, specific etiologic factors cannot be identified. ${ }^{29}$ In our study, no underlying cause for the natal/neonatal teeth was apparent, but it could have been because of the superior placement of the tooth germ. Natal teeth can occur as an isolated dental finding, but many times they are associated with syndromes and developmental disturbances. ${ }^{5,12-15}$ In one patient (case 7) in the present study, neonatal teeth had led to the formation of fibrous hyperplasia which is rarely reported in the literature. ${ }^{30}$ Fibrous hyperplasia is a non-specific reactive lesion of soft tissues of unknown etiology usually associated with trauma or local irritation. There was no hereditary influence in any of the cases, and none of the cases showed syndromic features or systemic manifestations.

Considering the complications associated with natal/neonatal teeth, such as Riga-Fede disease, feeding problems, the possibility of infection, and hyper mobility, in most cases, extraction is the treatment of choice. However, in the interest of protecting the child this decision should be made carefully. Prophylactic administration of vitamin $\mathrm{K}$ (0.5-1 mg, intramuscular) is advocated because of the risk of hemorrhage as the commensal flora of the intestine might not have been established until the child is 10 days old, and vitamin $K$ is essen- 
tial for the production of prothrombin in the liver. ${ }^{31}$ For this reason, in patients 5 and 13 , extraction was done after the administration of vitamin $\mathrm{K}$.

\section{CONCLUSIONS}

The occurrence of natal/neonatal tooth is a rare phenomenon. When it occurs, it shows varied clinical characteristics and leads to different complications. Knowing how to manage these structures is essential for the overall well being of a child. Still, many more longitudinal and divergent studies of different ethnic groups are required to confirm the etiology and nature of the natal/neonatal teeth.

\section{REFERENCES}

1. Massler M, Savara BS. Natal and neonatal teeth: A review of 24 cases reported in the literature. J Pediatr 1950;36:349359.

2. Bjuggren G. Premature eruption in primary dentition. A clinical and radiological study. Swed Dent J 1973;66:343-355.

3. Bodenholf J. Natal and neonatal teeth. Dent Abstract 1960;5:485-488

4. Hals H. Natal and neonatal teeth: Histological investigation in two brother. Oral Surg Oral Med Oral Pathol 1975;10:509521.

5. Bigeard L, Hemmerle J, Sommermater Jl. Clinical and ultra structural study of the natal tooth: enamel and dentine assessments. J Dent Child 1966;63:23-31.

6. Ooshima T, Mihara J, Saito T, Sobue S. Eruption of tooth-like structure following the exfoliation of natal tooth: report of case. ASDC J Dent Child 1986;53:275-278.

7. Kates GA, Needleman HL, Holmes LB. Natal and neonatal teeth - a clinical study. J Am Dent Assoc 1984;109:441-443.

8. Leung AK. Management of natal teeth. J Am Dent Assoc 1987;114:762.

9. Leung AKC. Natal teeth. Am J Dent Child 1986;140:249-251.

10. Anderson RA. Natal and neonatal teeth: histological investigation of two black females. J Dent Child 1982;49:300-303.

11. Alaluusua S, Kivirantha H, Leppaniemi A, Holtta P, Lukinmaa PL, Lope L. Natal and neonatal teeth in relation to environmental toxicants. Pediatr Res 2002;52:652-655.

12. Fonseca MA, Mueller WA. Hallerman-Streiff syndrome: case report and recommendations for dental care. J Dent Child 1995;61:334-337.

13. Oshihi M, Murakami E, Halta T, Naruse T, Sugino M, Inomata H. Hallermann-Streiff syndrome and its oral implications. $J$ Dent Child 1986;53:32-37.

14. Liu HH, Chen CJ, Miles DA. Epidermolysis bullosa simplex: Review and report of case. ASDC J Dent Child 1998;65:349353.
15. Weiss H, Croset AD. Chondroectodermal dysplasia. J Pediatr 1955;46:268-275.

16. Goncalves FA, Birmani EG, Sugayai NN, Melo AM. Natal teeth: Review of literature and report of an unusual case. Braz Dent J 1998;9:53-56.

17. Zhu J, Kind D. Natal and neonatal teeth. $J$ Dent Child 1995;62:123-128.

18. Diaz-Romero RM, Sho-Hass F, Benitez-Tirano C, Fernandez-Carrocerra L. Anomalias de la cavidad oral en neonates mexicanos. Bol Med Hosp Infant Mex 1991;48:832-835.

19. Alvarez MP, Crespi PV, Shanske AL. Natal molars in Pfeiffer syndrome type 3: A case report. J Clin Pediatr Dent 1993;18:21-24.

20. Delbem AC, Faraco Junior IM, Percinoto C, Delbem AC. Natal teeth: Case report. J Clin Pediatr Dent 1996;20:325-327.

21. El Khatib K, Abouchadi A, Nassih M, Rzin A, Jidal B, Danino A. Natal teeth: Study of five cases. Rev Stomatol Chir Maxillofac 2005; 106:325-327.

22. Anegundi RT, Sudha P, Kaveri H, Sadanand K. Natal and neonatal teeth: A report of four cases. J Indian Soc Pedod Prev Dent 2002;20:86-92.

23. To EW. A study of natal teeth in Hong Kong Chinese. Int $J$ Pediatr Dent 1991;1:73-76.

24. Ziai MN, Bock DJ, Da Silveira A, Daw JL. Natal teeth: a potential impediment to naso-alveolar molding in infants with cleft lip and palate. J Craniofac Surg 2005;16:262-266.

25. Hedge RJ. Sublingual traumatic ulceration due to neonatal teeth (Riga-Fede disease). J Indian Soc Pedod Prev Dent 2005;3:51-52.

26. Buchanan S, Jenkins CR. Riga-Fedes syndrome: natal or neonatal teeth associated with tongue ulceration. Case report. Aust Dent J 1997;42:225-227.

27. Tomizawa M, Yamada $Y$, Tonouchi K, Watanabe $H$, Noda $T$. Treatment of Riga-Fede's disease by resin-coverage of the incisal edges and seven cases of natal and neonatal teeth. Shoni Shikagaku Zasshi 1989;27:182-190.

28. Goho C. Neonatal sublingual traumatic ulceration (Riga-Fede disease): reports of cases. ASDC J Dent Child 1996;63:362-364.

29. Masatomi Y, Abe K, Ooshima T. Unusual multiple natal teeth: case report. Pediatr Dent 1991;13:170-172.

30. Singh S, Subba Reddy VV, Dhananjaya G, Patil R. Reactive fibrous hyperplasia associated with a natal tooth. J Indian Soc Pedod Prev Dent 2004;22:183-186.

31. Barfiwala DR. Natal and neonatal teeth: a review of 50 cases. J Indian Soc Pedod Prev Dent 1996;14:21-23. 